\title{
Building a Digital Twin for the Management of Pressurised Collective Irrigation Systems
}

\author{
Madalena Moreira 1,2 [0000-0002-2174-6982], Sandra Mourato ${ }^{1,3}$ [0000-0001-9545-2584], Carlos Ro- \\ drigues $^{1,4}$ [0000-0001-6847-0170], Sandra Silva ${ }^{10000-0002-0317-3631]}$, Rita Guimarães ${ }^{1,4 \text { [0000-0001- }}$ \\ 6641-3834], Carlos Chibeles ${ }^{\text {[0000-0002-1771-3993] }}$ \\ ${ }^{1}$ MED - Mediterranean Institute for Agriculture, Environment and Development, Pólo da Mitra, \\ Ap. 94, 7006-554 Évora, Portugal. sdeovs@gmail.com \\ ${ }^{2}$ Department of Architecture, University of Évora, Escola dos Leões, Estrada dos Leões, 7000- \\ 208 Évora, Portugal.mmvmv@uevora.pt \\ ${ }^{3}$ ESTG - Polytechnic Institute of Leiria, Portugal; Sandra.mourato@ipleiria.pt \\ ${ }^{4}$ Department of Rural Engineering, University of Évora, Pólo da Mitra, Ap. 94, 7006-554 \\ Évora, Portugal.camr@uevora.pt; rcg@uevora.pt \\ ${ }^{5}$ Odivelas Associations of Irrigation Water Users, 7900-562 Ferreira do Alentejo - Portugal. \\ cchibeles@aboro.pt
}

\begin{abstract}
Digital Twins (DT) can be exploited to improve Collective Irrigation Systems (CIS) performance and be fundamental for decision-making. Developing a DT is an enormous challenge with continuous adjustments and learning from the physical system. Agriculture represents one of the most water demanding sectors, and changing from gravity to pressurised water distribution turning the efficient use of water and energy as one of the main purposes of managing pressurised CIS. The DT is created based on field and laboratory tests, a systematic application of hydraulic modelling, water balance, energy balance and performance indicators. The data connection between the physical system and the DT and data advanced analytics provides a means to the operational setting, optimising, studying scenarios, and adapting to external changes of the pressurised CIS. In this paper, the authors propose a methodology to build a DT of a primary and secondary pressurised CIS network to evaluate water use efficiency, global energy efficiency, pumping facilities efficiency and energy inefficiency associated with water losses. A preliminary application to Block 4, a pressurised subsystem of Odivelas CIS, is presented in Southern Portugal. It was possible to ascertain the great potential of the physical twin - digital twin set to understand system processes, the corrective measures, the priority of maintenance and management decision of the pressurised collective irrigation system. This formulation is a good way to move towards smart water management in CIS.
\end{abstract}

Keywords: Collective Irrigation Systems, Digital Twin, water balance, energy balance, performance indicators, EPANET. 